\title{
A case series of cavitary otosclerosis and its audiological association
}

Jia W, Singh A, Lingam R K, Pulickal G, Nguyen T

Fenestral Otosclerosis with cavitation

\section{Introduction}

Cavitary otosclerosis, also known as diverticula of the internal auditory meatus, is rarely described in the literature (pictures 1 \& 2). Historically it has been described as a part of the otosclerosis process. Recently it has been identified to occur independently, with no classical features of otosclerosis $(1,2)$. Its clinical relevance is not entirely understood. The aim is to correlate cavitary otosclerosis, identified on computed tomography (CT), with audiological tests to identify a clinical significance.

\section{Methods}

10 patients with bilateral otosclerosis were identified through our multi-disciplinary otological radiology meetings, with signs of cavitation (15 temporal bones) in the internal acoustic meatus on CT. 10 patients (19 temporal bones) with only fenestral otosclerosis were also identified for comparison.

\section{Result}

10 temporal bones had cavitations with fenestral otosclerosis (figure 1 ), of which 7 (70\%) correlated with a mixed hearing loss, 2 (20\%) correlated with a conductive hearing loss and $1(10 \%)$ correlated with normal hearing.

5 temporal bones contained cavitations with both fenestral and retrocochlear disease (figure 2), of which $3(60 \%)$ had a mixed hearing loss, 1 (20\%) had a sensorineural hearing loss and 1 (20\%) had a conductive hearing loss.

19 temporal bones with only fenestral otosclerosis (figure 3) were identified. Of which, 5 (26.32\%) correlated with a mixed hearing loss, $13(68.42 \%)$ correlated with a conductive hearing loss, and 1 $(5.26 \%)$ correlated with normal hearing.

\section{Conclusion}

Cavitations have been shown to occur independently of otosclerosis and are associated more with a sensorineural hearing loss (1). However, cavitations with fenestral disease appear to correlate more with a mixed hearing loss, compared to fenesteral otosclerosis with no cavitation. Perhaps cavitations contribute to a sensorineural element in otosclerosis when present. Also, our radiology team is reporting more of this entity in radiological reports due to raised awar

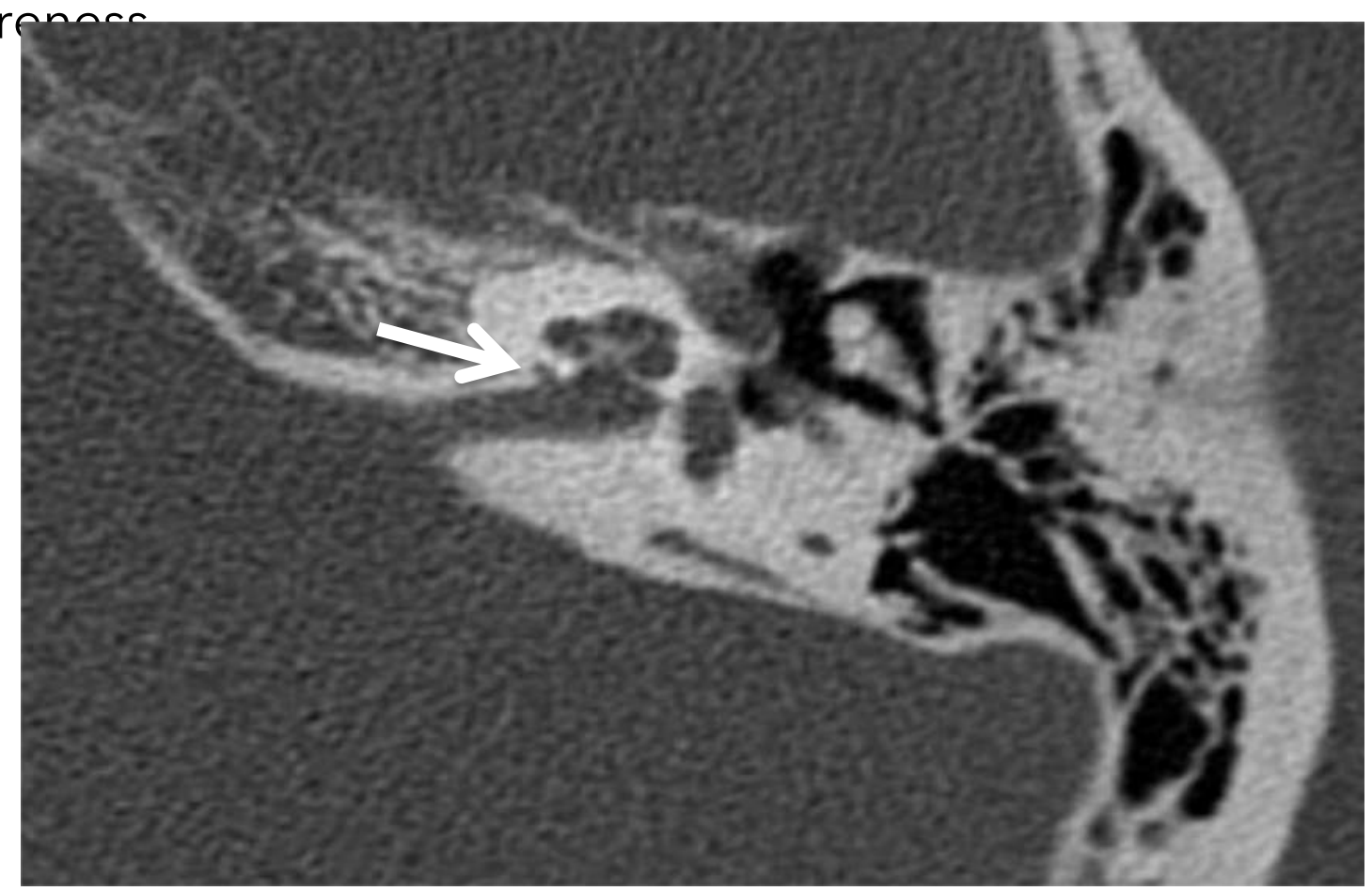

Picture 1: Axial view of the temporal bone, a cavitation can be seen in the anterior wall of the internal acoustic meatus ( see arrow)

\begin{tabular}{|l|}
\hline References \\
1. Pippin et al. (2017). Prevalence of Internal Auditory Canal Diverticulum and Its Association \\
with Hearing Loss and Otosclerosis. American Journal of Neuroradiology. 38. \\
10.3174/ajnr.A5399. \\
2. Puac.P et al, Cavitary Plaques in Otospongiosis: CT Findings and Clinical Implications. \\
American Journal of Neuroradiology Apr 2018, DOI: 10.3174/ajnr.A5613
\end{tabular}

2. Puac.P et al, Cavitary Plaques in Otospongiosis: CT Findings and Clinical Implications

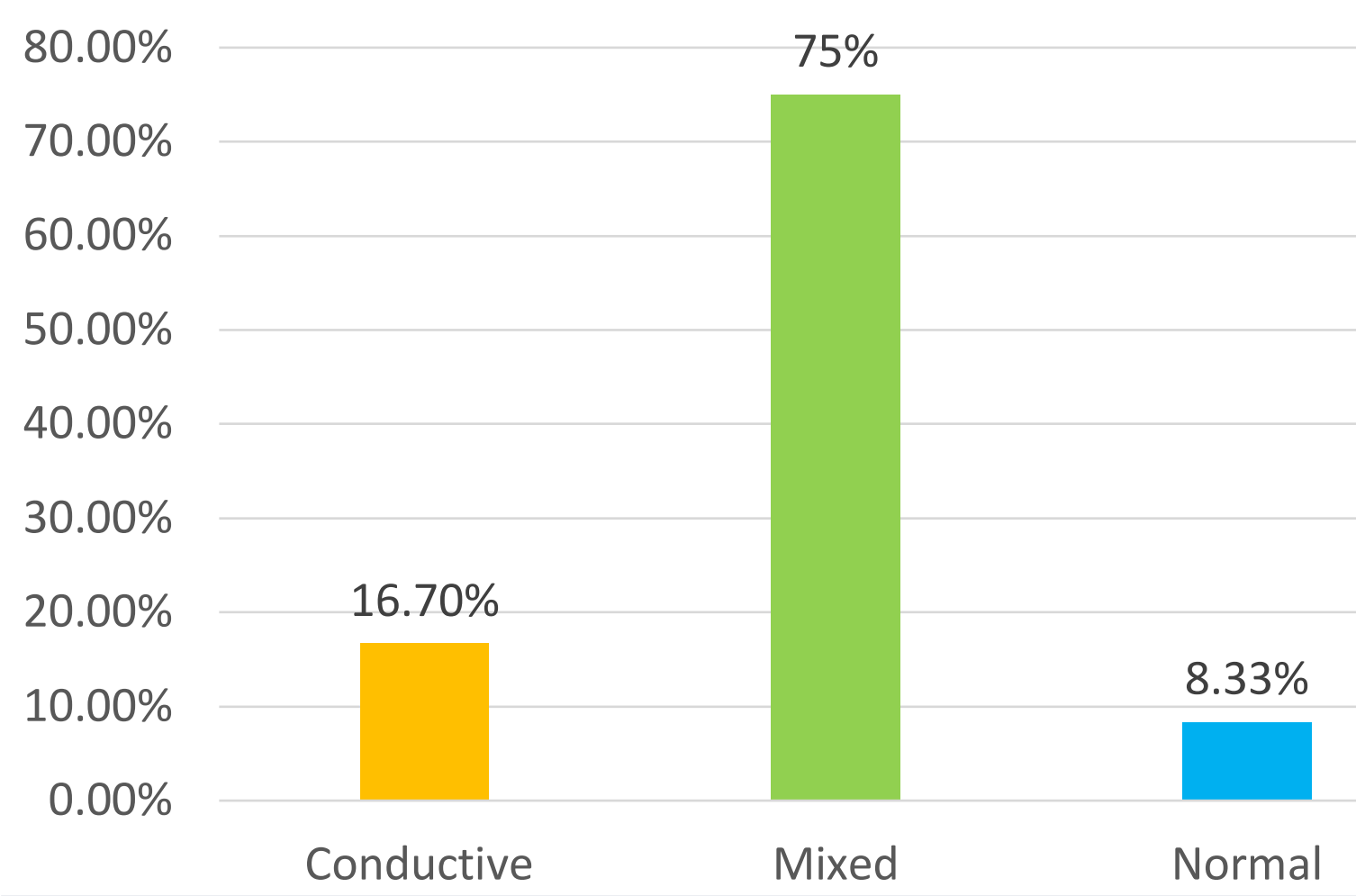

Figure 1: Graph demonstrating the type of hearing loss associated with cavitation in the internal acoustic meatus with fenestral otosclerosis. Mixed hearing loss was the most prominent.

Fenestral and Retrofenestral Otosclerosis with cavitation

$60.00 \%$

$55.56 \%$

$50.00 \%$

$40.00 \%$

$30.00 \%$

$20.00 \%$

$10.00 \%$

$0.00 \%$

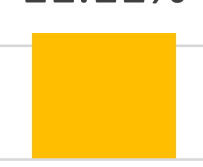

Conductive

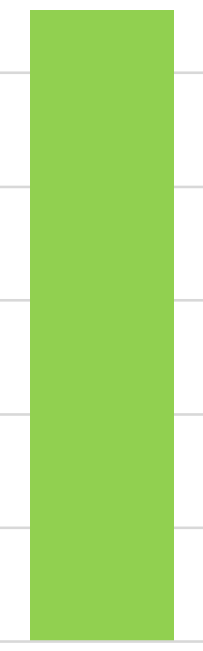

$33.33 \%$

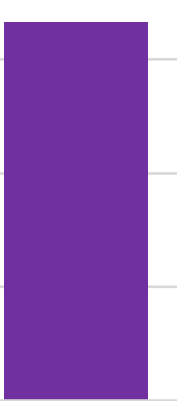

Mixed

Sensorineural

Figure 2: Graph demonstrating the type of hearing loss associated with cavitation in the internal acoustic meatus in otosclerosis with fenestral and retrofenestral disease. Mixed hearing loss was the most prominent.

$80.00 \%$ Fenestral Otosclerosis only

$70.00 \%$

$60.00 \%$

$50.00 \%$

$40.00 \%$

$30.00 \%$

$20.00 \%$

$10.00 \%$

$0.00 \%$ $68.42 \%$

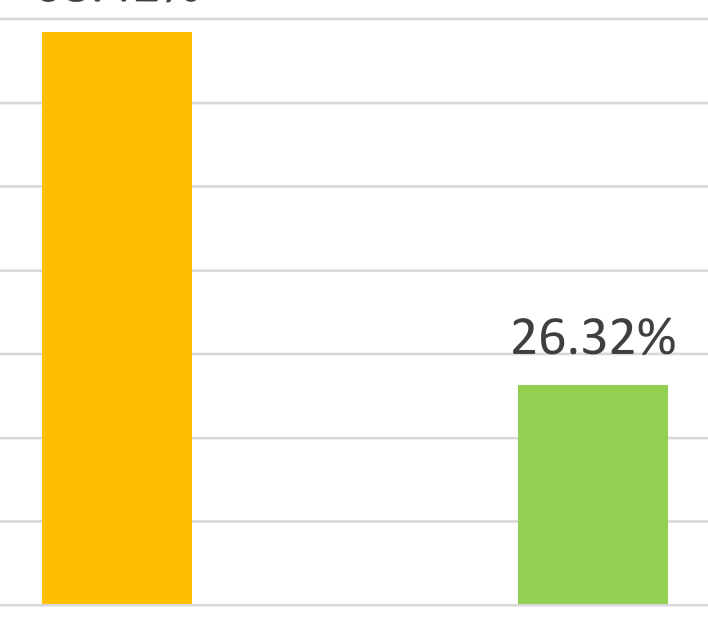

$5.26 \%$

Conductive

Mixed

Normal

Figure 3: Graph demonstrating the type of hearing loss associated with fenestral otosclerosis only. Conductive hearing loss was the most prominent

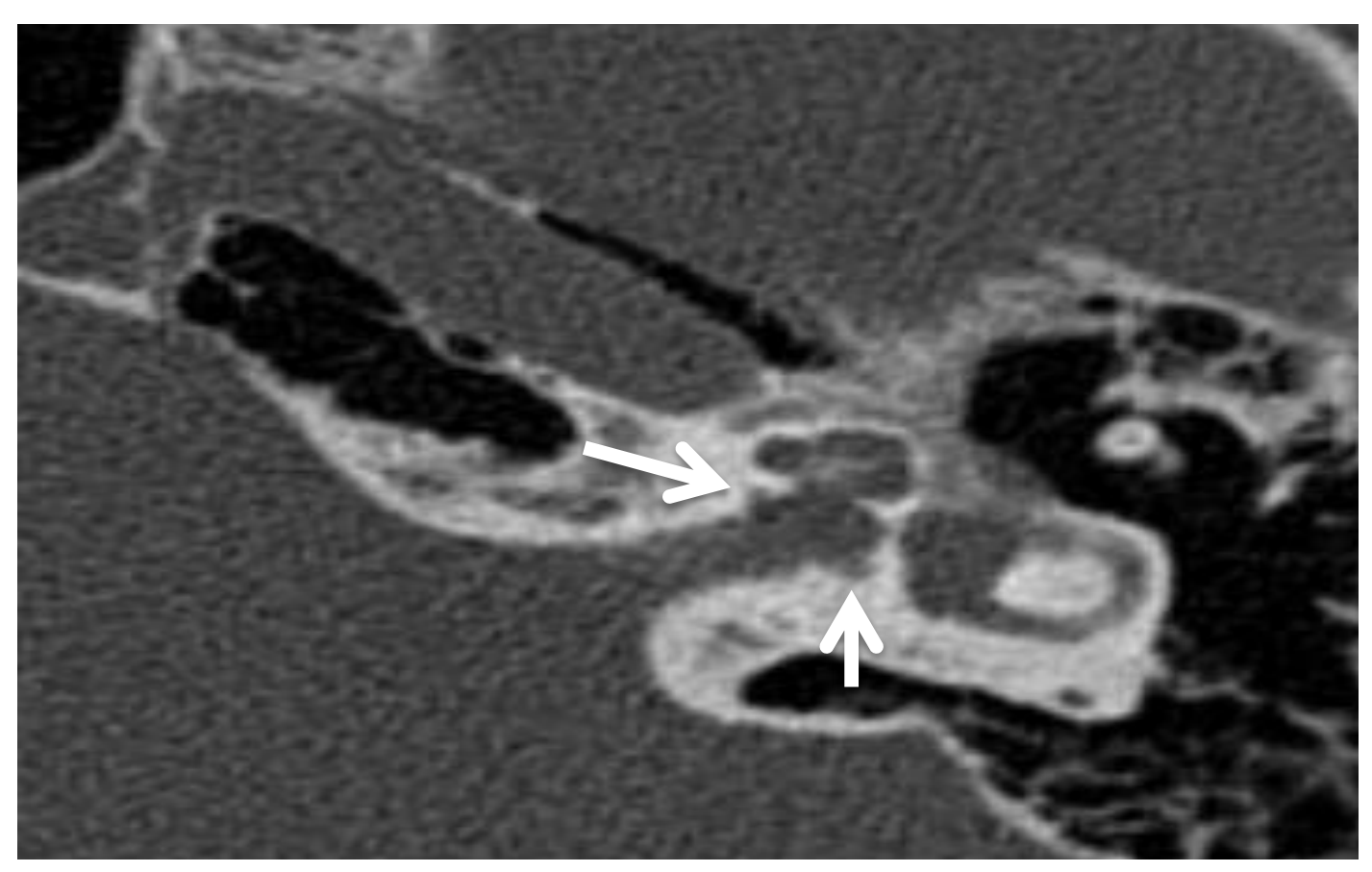

Picture 2: Axial view of the temporal bone, cavitations are seen in both anterior and posterior internal acoustic meatus ( see arrows) 